NOTICE: this is the author's version of a work that was accepted for publication in Chemosphere. Changes since it was submitted for publication. A definitive version was subsequently published in Chemosphere 70(8), International http://creativecommons.org/licenses/by-nc-nd/4.0.

\title{
8 Modeling of metal binding in tropical Fluvisols and Acrisols treated with
}

\section{9 biosolids and wastewater}

10 Nguyen Manh Khai ${ }^{\mathrm{a},{ }^{*}}$, Ingrid Öborn ${ }^{\mathrm{a}}$, Steve Hillier ${ }^{\mathrm{b}}$ and Jon Petter Gustafsson ${ }^{\mathrm{c}}$

$11{ }^{a}$ Dep of Soil Sciences, Swedish University of Agricultural Sciences (SLU), P.O. Box 7014, SE-

1275007 Uppsala, Sweden

$13{ }^{\mathrm{b}}$ Macaulay Institute, Craigiebuckler, Aberdeen, AB15 8QH, UK

$14{ }^{\mathrm{c}}$ Dep of Land and Water Resources Engineering, Royal Institute of Technology (KTH),

15 Brinellvägen 28, SE- 10044 Stockholm, Sweden

$16{ }^{*}$ Corresponding author: Tel.+46 18 671257; fax +46 18 672795, E-mail:

17 Nguyen.Manh.Khai@mv.slu.se

18 Abstract

There is growing concern about the accumulation of metals in tropical agricultural

20 soils. Experimental results from batch studies were combined with results from the multi-

21 surface models to test whether the multi-surface models (DSG and DNG model) could

22 describe metal binding. The multi-surface models were included soil sorption surfaces, i.e.

23 iron hydroxides (Diffuse Layer Model), organic matter (Stockholm Humic Model and NICA-

24 Donnan Model), and phyllosilicate clay (Gaines-Thomas). The dissolution of Cd, Cr(III), Cu, 
$24 \mathrm{Mn}, \mathrm{Pb}$ and $\mathrm{Zn}$ was investigated. We found that for total dissolved $\mathrm{Cd}, \mathrm{Cu}$ and $\mathrm{Zn}$ the two multi-surface models being tested provided very good model fits for all soils, as evidenced by low root-mean square errors between model predictions and observations. The results suggest that organic matter is an important sorbent for many metals in these soils. However, poor fits were obtained for $\mathrm{Cr}(\mathrm{III}), \mathrm{Mn}$ and $\mathrm{Pb}$ for all soils. The study also suggests that the $\mathrm{pH}$ is the main factor that controls the solubility of metals in tropical Fluvisols and Acrisols subjected to application of biosolids and wastewater, and that advanced multi-surface models can be used to simulate the binding and release of many trace metals.

Introduction

Use of wastewater and biosolids in food production systems is a subject of increasing concern. Due to high contents of plant nutrients and organic matter, wastewater and biosolids are beneficial as fertilizer as well as for irrigation and soil amendment. However, as these wastes are products of human society, increased concentrations of potential toxic substances including trace metals are found in wastewater or biosolids, which may accumulate in the soil environment (e.g. Bergkvist et al., 2005). Chemical speciation governs the bioavailability, toxicity and transport of trace metals in natural systems (Stumm and Morgan, 1996). Adsorption is a major process responsible for accumulation of trace metals. The most important interfaces involved in trace metal adsorption in soils are colloidal particles of organic matter and inorganic colloids such as clays and metal (hydr)oxides (Ross, 1996).

Humic substances bind trace metals strongly and therefore they determine the behaviour and the fate of these metals in natural systems especially in the surface horizon of soils (Gustafsson et al., 2003). Several advanced modeling approaches have been developed to describe the speciation of cations in the presence of humic organic matter. Currently, the 
most advanced models for organic complexation are Model VI, NICA-Donnan and the

49 Stockholm Humic Model (SHM) (Tipping, 1998; Kinniburgh et al., 1999; Gustafsson, 2001).

By combining organic complexation models with models for oxide adsorption and ion

exchange it is possible to construct so-called multi-surface models, which may give a comprehensive description of metal binding to soils. Weng et al. (2001) used a multi-surface model to describe metal binding of Dutch sandy soils; they found that organic matter is the most important sorbent that controls the activity of most metals (e.g. $\mathrm{Cu}, \mathrm{Cd}, \mathrm{Ni}, \mathrm{Zn}$ ), but for $\mathrm{Pb}, \mathrm{Fe}$ oxide was more important. Similar results were obtained by Dijkstra et al. (2004) for contaminated soils.

The overall objective of this study was to examine whether multi-surface models could be used to describe trace metal binding in some tropical soils amended with biosolids and wastewater. Organic complexation models were combined with a surface complexation model for Fe and $\mathrm{Al}$ (hydr)oxides and with ion exchange to phyllosilicate clays. The resulting models were applied to predict dissolved $\mathrm{Cd}, \mathrm{Cr}, \mathrm{Cu}, \mathrm{Pb}, \mathrm{Mn}$ and $\mathrm{Zn}$ in soil solutions from batch experiments; the model results were compared with these measurements.

\section{Materials and methods}

Soil sampling site

Samples from eight agricultural soils were collected from peri-urban areas in 4 provinces of northern Vietnam including Hanoi, Nam Dinh, Ha Tay and Vinh Phuc (Table 1).

67 The sampled areas are located in the Red River delta and lowland areas where the parent 68 material is alluvial deposits. These are derived mainly from sedimentary (sandstone, shale, schist) and metamorphic (clay, slate, phyllite, mica, gneiss) material, together with some acid igneous sources (rhyolite, granite and liparite). The annual rainfall is between 1500 and 2000 $\mathrm{mm}$, and more than $50 \%$ of the rainfall is concentrated during June to August. The mean 
monthly temperature varies between 17 and $29^{\circ} \mathrm{C}$, with the warmest period from June to August and the coldest during December and January.

Hanoi site: The soil sample (TTBB) was collected in a rice field in Bang B village, belonging to Hoang Liet commune, Thanh Tri district, a peri-urban area located downstream from Hanoi City. The farmers in this area started to use municipal wastewater from Hanoi City for irrigation in the 1960s. The soil is a Eutric Fluvisol according to WRB (FAO-ISRICISSS, 1998).

Nam Dinh site: The soil sample (HL) was collected in the Hong Long cooperative, a peri-urban area of Nam Dinh City, Nam Dinh province, $100 \mathrm{~km}$ south-east of Hanoi. This area has been using municipal wastewater for irrigation since the 1980 s and rice is the main cultivated crop. The soil is a Humi-Endogleyic Fluvisol (Eutric) (FAO-ISRIC-ISSS, 1998).

Vinh Phuc site: Soil samples (BoM11, BoM14 and BoM16) were collected from a field experiment with biosolids (chicken manure). Three soil samples were taken representing three different application rates (Table 1). Vegetables were grown at this site, predominantly cabbage (Brassica oleacea L.) and squash (Benicasa hispida L.). The site is located in the Vinh Phuc province, $25 \mathrm{~km}$ north of Hanoi. The soil is a Haplic Acrisol (FAO-ISRIC-ISSS, 1998). another experimental site with biosolids representing three different application rates of composted manure (Table 1). The main crop was rice. The studied site is located in the Ha

92 Tay province, $20 \mathrm{~km}$ north-west of Hanoi. The soil is a Cambic Fluvisol (FAO-ISRIC-ISSS, 93 1998). 
Soil sampling was conducted in June 2004 with a stainless steel corer. Five subsamples of topsoil $(0-20 \mathrm{~cm})$ were collected within a circle of $2 \mathrm{~m}$ diameter for the Ha Tay and Vinh Phuc sites and within the plot (approximately $250 \mathrm{~m}^{2}$ ) for the Nam Dinh and Hanoi sites. The subsamples were bulked into one sample in the field. After air drying at room temperature, the soil samples were sieved to remove particles $>2 \mathrm{~mm}$, and then stored in plastic bags. The $<2 \mathrm{~mm}$ fraction was used for analyses.

\section{Soil analysis}

Soil texture was determined using standard methods (wet sieving and pipette method), following dissolution of carbonate by $1 \mathrm{M} \mathrm{NaOAc}(\mathrm{pH}$ 5) and removal of organic matter by $\mathrm{H}_{2} \mathrm{O}_{2}$ (Gee and Bauder, 1986). After treatment by $4 \mathrm{M} \mathrm{HCl} \mathrm{(1:1} \mathrm{soil:solution} \mathrm{ratio)} \mathrm{for} \mathrm{the}$ dissolution of carbonates, finely ground samples were analyzed for total organic carbon (TOC) (Leco $\mathrm{CHN}^{\circledR} \mathrm{CHN} 932$ analyzer). The soil $\mathrm{pH}$ was measured in deionized $\mathrm{H}_{2} \mathrm{O}$ (1:5).

Soil samples were extracted with $1 \mathrm{M} \mathrm{NH}_{4} \mathrm{NO}_{3}(1: 2.5)$ for $2 \mathrm{~h}$ to quantify initial concentrations of sorbed $\mathrm{Ca}, \mathrm{Mg}, \mathrm{K}$ and $\mathrm{Na}$ (AAS, Perkin Elmer 300). Amorphous Fe oxide was extracted with $2.5 \%$ ascorbate (1:60) for $4 \mathrm{~h}$ (Kostka and Luther, 1994). Crystalline and non-crystalline forms of Fe were extracted by $1.7 \%$ sodium dithionite $(1: 60)$ for $16 \mathrm{~h}$ (van Reeuwijk, 1993). Amorphous Al-(hydr)oxides were extracted by $0.2 \mathrm{M}$ ammonium oxalate (1:100) for $4 \mathrm{~h}$ (van Reeuwijk, 1993). The analyses of Al and Fe were carried out by plasma emission spectroscopy (ICP-OES, Jobin-Yvon JY24) or by mass spectrometry (ICP-MS, Perkin Elmer ELAN 6100). Humic (HA) and fulvic acids (FA) were extracted twice with 0.1 $\mathrm{M} \mathrm{NaOH}$ (2 h). The centrifuged supernatants were pooled into one sample, which was analyzed for TOC with a Shimadzu TOC-5000 analyzer. After acidification to $\mathrm{pH} 2$ with $\mathrm{HCl}$, the rest of the sample was centrifuged, and the supernatant was analyzed for TOC (Shimadzu TOC-5000 analyzer). The latter fraction was assumed to represent the soil content of FA, whereas HA was calculated by difference. Extraction in $0.025 \mathrm{M} \mathrm{Na}_{2} \mathrm{H}_{2}$ EDTA (1:10) for $1.5 \mathrm{~h}$ 
120 (Streck and Richter, 1997) was used for potentially bioavailable metals (Cd, $\mathrm{Cr}, \mathrm{Cu}, \mathrm{Mn}, \mathrm{Pb}$

121 and $\mathrm{Zn}$ ) fraction. After centrifugation and filtration, metal concentrations were determined by mass spectrometry (ICP-MS). $12 \mathrm{~min}$, with $15 \mathrm{~g}$ of water and spray dried as per Hillier (1999). The resulting powders were

126 quantified by full-pattern fitting as described in detail by Omotoso et al., (2006). Uncertainty at $95 \%$ confidence is given by $\mathrm{X}^{0.35}$ (Hillier, 2003). X-ray powder diffraction (XRPD) patterns

128 were recorded on a Siemens D5000 instrument from $2-75^{\circ} 2 \theta$ using Cobalt K $\alpha$ radiation, in

$1290.02^{\circ}$ steps counting for $2 \mathrm{~s}$ per step. Clay fractions of $<2 \mu \mathrm{m}$ were obtained by timed

130 sedimentation, prepared as oriented mounts using the filter peel transfer technique and

131 scanned from $2-45^{\circ} 2 \theta$ counting for 1 second per $0.02^{\circ}$ step, in the air-dried state, after

132 glycolation, and after heating to $300^{\circ} \mathrm{C}$ for $1 \mathrm{~h}$. Clay minerals identified were quantified using

133 a mineral intensity factor approach based on calculated XRPD patterns as described by Hillier 134 (2003). In batch experiments, $2 \mathrm{~g}$ soil was transferred to a $50 \mathrm{~mL}$ polypropylene centrifuge

137 tube. Various amounts of acid $\left(\mathrm{HNO}_{3}\right)$ or base $(\mathrm{NaOH})$ were added to the systems, so that

138 each system was studied at eleven different $\mathrm{pH}$ values, each analyzed in duplicate. Additional

$139 \mathrm{NaNO}_{3}$ was added to produce an ionic strength of approximately $0.02 \mathrm{M}$ in the suspensions.

140 The final volume of solution in the centrifuge tubes was $30 \mathrm{~mL}$. The centrifuge tubes were 141 capped and shaken for $7 \mathrm{~d}$ in an end-over-end shaker at $20^{\circ} \mathrm{C}$. After equilibration, the samples

142 were centrifuged for $20 \mathrm{~min}$ at $3000 \mathrm{rpm} .2 \mathrm{~mL}$ of the supernatant was taken for $\mathrm{pH}$

143 measurement. The remaining supernatant was filtered through a $0.2 \mu \mathrm{m}$ filter (Pall Acrodisc ${ }^{\circledR}$ 
144 PF syringe filter) and the filtrate was divided between two vessels, one was analyzed for TOC

145 and for anions $\left(\mathrm{Cl}^{-}, \mathrm{SO}_{4}{ }^{2-}, \mathrm{PO}_{4}{ }^{3-}\right)$ by ion chromatography (Dionex ICS-90), whereas the other

146 one was acidified $\left(0.5 \% \mathrm{HNO}_{3}\right)$ for measurement of dissolved metals using ICP-MS.

147 The multi-surface models, DSG and DNG model

148 We assumed that three reactive surfaces could account for the adsorption behaviour of

149 the soil. These three surfaces were iron/aluminum (hydr)oxide, organic matter and

150 phyllosilicate clay.

Binding to iron/aluminum (hydr)oxide: To take surface complexation to iron

152 (hydr)oxide surfaces into account, we used the Diffuse Layer Model (DLM) (Dzombak and

153 Morel, 1990) for specific binding of metal cations and (oxy)anions to hydrous ferric oxide

154 (HFO). The recommended specific surface area of $600 \mathrm{~m}^{2} \mathrm{~g}^{-1}$ for HFO was used to calculate

155 site concentrations for the amorphous iron and aluminum (hydr)oxides (Dijkstra et al., 2004).

156 The total amount of amorphous iron (hydr)oxides was calculated from Fe extracted with

157 ascorbate and represented by HFO in the model. The amount of crystalline iron (hydr)oxides

158 was calculated from the difference between Fe-dithionite and Fe-ascorbate. However, site

159 concentrations of crystalline iron (hydr)oxides were calculated using a specific surface area of

$160100 \mathrm{~m}^{2} \mathrm{~g}^{-1}$ (Dijkstra et al., 2004), therefore, to include crystalline iron (hydr)oxides in the

161 model, we converted the suspension density of crystalline Fe (hydr)oxides to HFO equivalents

162 by dividing it with 6 . In addition, amorphous aluminum (hydr)oxides were considered, for

163 which HFO was taken as a surrogate sorbent in the model (Dijkstra et al., 2004). This

164 contribution was calculated from Al extracted with ammonium oxalate.

165 Binding to soil organic matter (SOM): The SHM and the Non Ideal Competitive

166 Adsorption Donnan model (NICA-Donnan) were used. Both are available in Visual MINTEQ

167 (Gustafsson, 2007). The SHM is a discrete-site / electrostatic model in which the HA or FA is 
assumed to have eight proton-binding sites with different acid-base characteristics (for details

169 see Gustafsson, 2001; Gustafsson et al., 2007). The principles of the NICA-Donnan model

170 have been discussed in detail elsewhere (Kinniburgh et al., 1999; Milne et al., 2003). For

171 parameters and parameter values of the SHM and NICA-Donnan models see the

172 Supplementary material; the metal-binding parameters were those used by Linde et al. (2007)

173 for the SHM and by Milne et al. (2003) for the NICA-Donnan model.

Binding to phyllosilicate clay minerals: The Gaines-Thomas equation was used to simulate ion exchange to phyllosilicate clays. For all cations, the selectivity coefficient was set to unity. To estimate the cation exchange capacity of the latter $\left(\mathrm{CEC}_{\text {clay }}\right)$, soil samples from the $\mathrm{C}$ horizon of the Acrisols (60-70 $\mathrm{cm}$ depth, where the TOC was low) were analyzed for the total cation exchange capacity $\left(\mathrm{CEC}_{\text {soil }}\right)$ and TOC $(\%)$. The $\mathrm{CEC}_{\text {clay }}$ for these $\mathrm{C}$

179 horizons were calculated from the equation below given by van Reeuwijk (1993), and the 180 resulting $\mathrm{CEC}_{\text {clay }}$ was assumed to be valid also for the A horizon since XRD analyses had shown that the composition of clay minerals was similar in the $\mathrm{A}$ and $\mathrm{C}$ horizons.

$$
\mathrm{CEC}_{\text {clay }}=\frac{100}{\% \text { clay }}\left(\mathrm{CEC}_{\text {soil }}-3.5 \times \mathrm{TOC}\right)
$$

For the Fluvisols, $\mathrm{CEC}_{\text {clay }}$ was taken from literature data as $0.1 \mathrm{~mol}_{\mathrm{c}} \mathrm{kg}^{-1}$ (Nguyen et al., 2001).

The difference between the DSG and DNG models was that the former used the SHM to describe metal binding onto SOM, whereas the DNG used the NICA-Donnan model. Both

187 models used the DLM for oxide adsorption and the Gaines-Thomas equation for ion

188 exchange. To apply the models, we used the chemical equilibrium program Visual MINTEQ

189 (Gustafsson, 2007), which also contains relevant solution complexation constants. 
192 concentrations of metals and competing cations. In this study the geochemically active concentrations were estimated mainly from extractions: The $\mathrm{NH}_{4} \mathrm{NO}_{3}$ extraction results were used for base cations $\left(\mathrm{Na}^{+}, \mathrm{K}^{+}, \mathrm{Ca}^{2+}\right.$ and $\left.\mathrm{Mg}^{2+}\right)$, metals $\left(\mathrm{Cd}^{2+}, \mathrm{Cr}^{3+}, \mathrm{Cu}^{2+}, \mathrm{Mn}^{2+}, \mathrm{Pb}^{2+}\right.$ and $\mathrm{Zn}^{2+}$ ) were estimated from EDTA extraction. It was assumed that $\mathrm{Cr}(\mathrm{III})$ and $\mathrm{Mn}(\mathrm{II})$ were the

196 dominating redox forms of $\mathrm{Cr}$ and $\mathrm{Mn}$. To account for the effect of $\mathrm{Cl}^{-}, \mathrm{SO}_{4}{ }^{2-}$ and $\mathrm{PO}_{4}{ }^{3-}$,

197 measured concentrations were used as input in the model. The adsorption of $\mathrm{SO}_{4}{ }^{2-}$ and $\mathrm{PO}_{4}{ }^{3-}$

198 to HFO was considered using the parameters of Dzombak and Morel (1990). Added $\mathrm{NO}_{3}{ }^{-}$ions

199 were assumed to behave conservatively. In addition, precipitation of Al hydroxide (non-

200 crystalline soil $\left.\mathrm{Al}(\mathrm{OH})_{3}\right)$ and ferrihydrite was permitted with $\log * K_{\mathrm{s}}$ of 8.6 and 3.0,

201 respectively, at the experimental temperature $\left(20^{\circ} \mathrm{C}\right)$.

Measured dissolved organic carbon (DOC) concentrations were used as input in the model, and it was assumed that $87 \%$ of DOM is active (Linde et al., 2007) and $50 \%$ of it is FA (Weng et al., 2002) for both multi-surface models.

Model-fit evaluation

Measured and simulated metal concentrations were compared through calculation of root-mean square errors (RMSEs) for the logarithms of the total dissolved concentration (Gustafsson and van Schaik, 2003). Because the metal determinations at low equilibrium concentrations were uncertain due to analytical limitations, data points with observed

210 concentrations of $<3.6 \times 10^{-10} \mathrm{M} \mathrm{Cd},<3.9 \times 10^{-9} \mathrm{M} \mathrm{Cr},<6.3 \times 10^{-9} \mathrm{M} \mathrm{Cu},<3.6 \times 10^{-8} \mathrm{M}$

$211 \mathrm{Mn},<1.9 \times 10^{-9} \mathrm{M}, \mathrm{Pb}$ and $<3.1 \times 10^{-8} \mathrm{M} \mathrm{Zn}$ were not included in the calculation of RMSEs.

\section{3. Results and discussion}

\section{Soil properties}


215 Vinh Phuc soils (Haplic Acrisols), the organic carbon and clay contents were lower than in the 216 other soils. The soil $\mathrm{pH}$ was slightly acid (between 6.0 and 6.6) except for the soil from the

217 plot in Vinh Phuc that had received the highest biosolid treatment (BoMl6) in which pH was

218 7.6. The clay fractions were dominated by expandable clays followed by illite (Table 1), the

219 illite being higher in the Fluvisols (30-40\%) and expandable clays relatively more abundant

$220(>70 \%)$ in the Acrisol. The expandable clays were all highly illitic mixed-layer illite-smectite and/or illite-vermiculite types, such as may be produced by the weathering of mica.

Muscovite mica was an important component of the bulk samples which further suggests that the expandable clays may be weathering products of mica. For bulk mineralogy, ammonium oxalate $\mathrm{Al}$ and $\mathrm{Fe}$, ascorbate-extractable $\mathrm{Fe}$, dithionite-extractable $\mathrm{Al}$ and $\mathrm{Fe}$, and the EDTAextractable metal concentrations, see the Supplementary material.

\section{Dissolved metals}

Figures 1-2 show the $\mathrm{pH}$ dependence of dissolved $\mathrm{Cu}, \mathrm{Zn}, \mathrm{Cd}, \mathrm{Pb}, \mathrm{Mn}$ and $\mathrm{Cr}$ (III) of all experimental soils. The concentration of dissolved metals was low at high $\mathrm{pH}$ values. The dissolved concentration increased with decreasing $\mathrm{pH}$, particularly at $\mathrm{pH}$ lower than 5. Most total dissolved metal concentrations were lowest in the $\mathrm{pH}$ range of 5-7. When $\mathrm{pH}$ is higher

231 than 7, metal solubility in soil solution (e.g. $\mathrm{Cu}$ and $\mathrm{Zn}$ ) tends to be increased because of

232 increased dissolution of metal-complexing organic ligands (Gustafsson et al., 2003).

\section{Modeling metal solubility in soils}

234 Optimized value of humic and fulvic acid proportion of the total organic matter that can be considered as 'active' HA and FA 
237 (Gustafsson and van Schaik, 2003; MacDonald and Hendershot, 2006). The ratio of active

238 HA to FA was assumed to equal that determined by $\mathrm{NaOH}$ extraction. In this work we

239 adjusted the sum of 'active' HA and FA using the procedure of Weng et al. (2001): 'active'

240 HA and FA was changed until organically bound $\mathrm{Ca}^{2+}, \mathrm{Mg}^{2+}, \mathrm{Na}^{+}$, and $\mathrm{K}^{+}$as calculated by the

241 model equalled the $\mathrm{CEC}_{\mathrm{OM}}$, which was calculated as the difference between the effective CEC

242 determined by $\mathrm{NH}_{4} \mathrm{NO}_{3}$ extraction and the estimated value of $\mathrm{CEC}_{\text {clay. }}$. For each soil, this

243 calculation was made for the data points where no acid or base was added.

The optimized value of $f_{\mathrm{HS}-\text { tot }}$ (the mass fraction of active humic matter (HS=HA+FA) compared to the total organic matter content) ranged from 0.28 to 0.50 for the DSG model, and from 0.27 to 0.48 for the DNG model (Table 2). The optimized value of HS was of the same magnitude as the content determined from base extraction. This indicated that the base extraction may provide a reasonable estimate of the 'active' HS in these Vietnamese soils.

\section{Simulation of dissolved metal concentrations}

The fits with the DSG and DNG models are shown in Fig. 3. These fits are predictions based on the optimized HS values for individual soils.

The model simulations for $\mathrm{Zn}$ in most cases agreed rather well with the observations. The overall RMSE value was 0.44 for DSG model and 0.53 for DNG model (Table 3). Also for $\mathrm{Cu}$, the simulations in most cases corresponded rather well with measured data for all soils. The overall RMSE values were 0.30 and 0.34 for DSG and DNG model, respectively.

256 The model results showed that the proportion of $\mathrm{Cu}$ bound to SOM accounted for the highest 257 proportion of sorbed $\mathrm{Cu}(92-98 \%$, Table 3 and Supplementary material). The predominance of $\mathrm{SOM}$ as a $\mathrm{Cu}$ sorbent across the $\mathrm{pH}$ range investigated is in agreement both with earlier observations and modeling results (McGrath et al., 1988; Weng et al., 2001; Dijkstra et al., 
2004). For $\mathrm{Zn}, \mathrm{SOM}$ is a significant sorbent, but at high $\mathrm{pH}$ the model results suggest that adsorption of $\mathrm{Zn}$ on HFO should also be considered.

The model fits for Cd were very good for all soils. The overall RMSE for Cd was 0.44 for DNG model. The RMSE was slightly improved to 0.31 when simulated by DSG model.

The results indicated that the $\mathrm{Cd}$ binding was determined mainly by complexation to organic matter. Models gave good fit for Mn when the $\mathrm{pH}$ lower than 6 (Fig. 2). However, dissolved Mn was not satisfactorily simulated when the $\mathrm{pH}$ higher than 6, neither with DSG nor with DNG model (the overall RMSE $=1.40$ and 1.07 , respectively). In most cases, the DSG as well as DNG model prediction overestimated dissolved Mn possibly due to Mn oxidation and formation of $\mathrm{MnO}_{2}$ under these conditions. SOM is dominant affinity for metal binding e.g. $\mathrm{Cu}, \mathrm{Zn}$ and $\mathrm{Cd}$. In addition, the adsorption of $\mathrm{Cd}$ and $\mathrm{Zn}$ on phylocilicate clays become more important at $\mathrm{pH}$ values below 3.5, while at $\mathrm{pH}$ above 7 the adsorption of those metals on HFO should be considered (Figure S1, supplemental data).

The model-predicted value of total dissolved Cr(III) in most cases agreed poorly with the observed total dissolved concentration of Cr (Fig. 3), both the DSG and DNG model underestimated the dissolved $\mathrm{Cr}$ (III) concentration. One possible reason may be uncertain complexation constants; for example the surface complexation constant for HFO suggested by Dzombak and Morel (1990) is only an estimate based on a linear free-energy relationship. Alternatively, the poor model fit can be explained by poor efficiency of the EDTA solution in removing $\mathrm{Cr}$ (III) from oxides and organic matter. 
284 showed that $\mathrm{Pb}$ is relatively strongly bound to $\mathrm{Fe}$ oxides at $\mathrm{pH}>4$. One reason for the poor fit

285 could be due to the fact that $\mathrm{Pb}$ is even more strongly bound to $\mathrm{Fe}$ and $\mathrm{Mn}$ oxides than the

286 models suggest. The importance of Mn oxides has been stressed earlier (McKenzie, 1980). In

287 our case, we did not include Mn oxide in the model and XRPD data indicate that a variety of

288 different crystalline iron oxides are present in the samples so that they may require a more

289 complex parameterization. Another possibility is that the models underestimate $\mathrm{Pb}$ binding to

290 organic matter. The finding that $\mathrm{Pb}$ binding to soil is underestimated with generic model

291 parameters for metal-humic complexation is in agreement with previous studies (Weng et al.,

292 2002; MacDonald and Hendershot, 2006; Linde et al., 2007).

\section{Conclusions}

Although the organic carbon contents in top soil layer were small, the success of the

model approach indicates that the organic matter is the most important soil component that

296 controls the solubility of metals in the studied soils, certainly for some trace metals such as

$297 \mathrm{Cd}, \mathrm{Cu}$ and $\mathrm{Zn}$. The multi-surface models provided good model fits for the total dissolved

298 concentrations of $\mathrm{Cd}, \mathrm{Cu}$ and $\mathrm{Zn}$ in all studied soils. For $\mathrm{Pb}, \mathrm{Cr}$ (III) and $\mathrm{Mn}$, however,

299 modeling was not successful with either the DSG nor the DNG model. Nonetheless, the

300 success of the models for $\mathrm{Cd}, \mathrm{Cu}$ and $\mathrm{Zn}$ indicates that the multi models can be used for

301 simulations of metal binding and release in tropical surface soils subjected to additions of

302 biosolids and wastewater, while further refinements are required for $\mathrm{Pb}, \mathrm{Cr}(\mathrm{III})$, and $\mathrm{Mn}$.

\section{Acknowledgements}

This work was mainly funded by SIDA-SAREC within the frame of the project

'Towards the mitigation of environmental and public health risks due to heavy metal contamination in irrigated rice based systems of Vietnam' (SWE-2005-317) and by the

307 Ministry of Education and Training (MOET) in Vietnam supporting the $\mathrm{PhD}$ study of $\mathrm{Mr}$ 
308 Nguyen Manh Khai. Many thanks to Dr Nguyen Cong Vinh and Dr Pham Quang Ha and their

309 co-workers at the National Institute for Soils and Fertilizers in Vietnam for giving us access to

310 field sites and for their assistance in soil sampling and sample preparation.

\section{Appendix A. Supplementary data} Supplementary data associated with this article can be found, in the online version.

\section{References}

314 Bergkvist, P., Berggren, D., Jarvis, N., 2005. Cadmium solubility and sorption in a long-term sludge-amended arable soil. J. Environ. Qual. 34, 1530-1538.

316 Dijkstra, J., Meeussen, J., Comans, R., 2004. Leaching of heavy metals from contaminated 317 soils: An experimental and modeling study. Environ. Sci. Technol. 38, 4390-4395.

318 Dzombak, D.A., Morel, F.M.M., 1990. Surface Complexation Modeling. Hydrous Ferric

FAO-ISRIC-ISSS, 1998. World Reference Base for Soil Resources. World Soil Resources Report 84. Food and Agriculture Organization of the United Nations, Rome.

Gee, G.W., Bauder, J.W., 1986. Particle-size analysis. In: Klute, A. (Ed). Methods Of Soil Analysis. Part 1 - Physical And Mineralogical Methods. American Society of

Gustafsson, J.P., 2001. Modeling the Acid-Base Properties and Metal Complexation of Humic Substances with the Stockholm Humic Model. J. Colloid Interf. Sci. 244, 102-112.

327 Gustafsson, J.P., 2007. Visual MINTEQ. Web:

328 http://www.lwr.kth.se/English/OurSoftware/vminteq/index.htm (January 2007). 
329 Gustafsson, J.P., van Schaik, J.W.J., 2003. Cation binding in a mor layer: batch experiments and modelling. Eur. J. Soil Sci. 54, 295-310.

331 Gustafsson, J.P., Pechova, P., Berggren, D., 2003. Modeling metal binding to soils: The role of natural organic matter. Environ. Sci. Technol. 37, 2767-2774.

333 Gustafsson, J.P., Persson, I., Berggren Kleja, D., van Schaik, J.W.J., 2007. Binding of

Hillier, S., 1999. Use of an air-brush to spray dry samples for X-ray powder diffraction. Clay Miner. 34, 127-135.

Hiller, S., 2003. Quantitative Analysis Of Clay And Other Minerals In Sandstones By X-ray Powder Diffraction (XRPD). In: Morad, S., Worden, R.H. (Eds.). Clay Mineral Cements in Sandstones. Blackwell Publishing Limited, Oxford, pp. 213-251.

341 Kinniburgh, D.G., van Riemsdijk, W.H., Koopal, L.K., Borkovec, M., Benedetti, M.F., Avena, M.J., 1999. Ion binding to natural organic matter: competition, heterogeneity, stoichiometry and thermodynamic consistency. Colloid Surface A 151, 147-166.

344 Kostka, J.E., Luther, G.W., 1994. Partitioning and speciation of solid-phase iron in salt-marsh sediments. Geochim. Cosmochim. Acta 58, 1701-1710.

Linde, M., Öborn, I., Gustafsson, J.P., 2007. Effects of changed soil conditions on the mobility of trace metals in moderately contaminated urban soils. Water Air Soil Pollut $183,69-83$. of northern soils near metal smelters. Environ. Pollut. 143, 228-240. 
McGrath, S.P., Sanders, J.R., Shalaby, M.H., 1988. The effects of soil organic matter levels on soil solution concentrations and extractabilities of manganese, zinc and copper. Geoderma 42, 177-188.

McKenzie, R.M., 1980. The adsorption of lead and other heavy metals on oxides of manganese and iron. Aust. J. Soil Res. 18, 61-73.

Milne, C.J., Kinniburgh, D.G., van Riemsdijk, W.H., Tipping, E., 2003. Generic NICADonnan model parameters for metal-ion binding by humic substances. Environ. Sci. Technol. 37, 958-971.

Nguyen, V.B., Dinh, B.D., Ho, Q.D., Bui, H.H., Dang, T.L., Thai, P., Nguyen, V.T., 2001. The Information Of The Major Vietnamese Soils. The Gioi Publishers, Hanoi (In Vietnamese).

Omotoso, O., Mccarty, D.K., Hillier, S., Kleeberg, R., 2006. Some successful approaches to quantitative mineral analysis as revealed by the 3rd Reynolds Cup contest. Clay Clay Miner. 54, 748-760.

Ross, S.M., 1996. Retention, Transformation And Mobility Of Toxic Metals In Soils. In: Ross, S.M. (Ed). Toxic Metals In Soil-Plants Systems. John Wiley \& Son, West Sussex, pp. 63-152.

Streck, T., Richter, J., 1997. Heavy metal displacement in a sandy soil at the field scale. 1. Measurements and parameterization of sorption. J. Environ. Qual. 26, 49-56.

Stumm, W., Morgan, J.J., 1996. Aquatic Chemistry: Chemical Equilibria And Rates In Natural Waters. John Wiley \& Sons, New York. 
372 Tipping, E., 1998. Humic ion-binding Model VI: An improved description of the interactions of protons and metal ions with Humic substances. Aquat. Geochem. 4, 3-47.

374 van Reeuwijk, L.P., 1993. Procedures For Soil Analysis. International Soil Reference and Infromation Centre (ISRIC), Wageningen.

376 Weng, L., Temminghoff, E.J.M., van Riemsdijk, W.H., 2001. Contribution of individual sorhents to the control of heavy metal activity in sandy soil. Environ. Sci. Technol. 35, 4436-4443.

379 Weng, L., Temminghoff, E.J.M., Lofts, S., Tipping, E. van Riemsdijk, W.H., 2002.

380 Complexation with dissolved organic matter and solubility control of heavy metals in a sandy soil. Environ. Sci. Technol. 36, 4804-4810. 

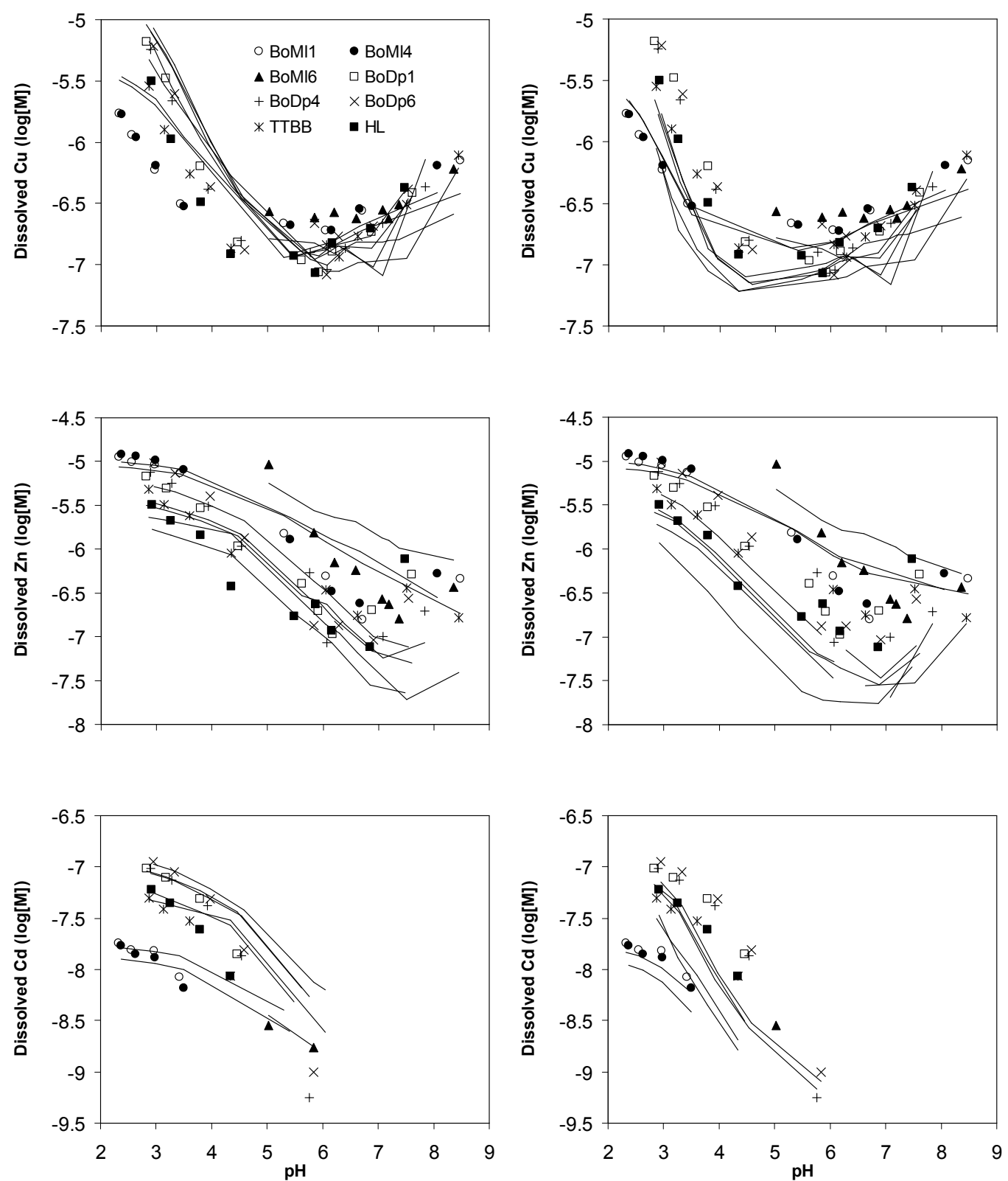

Fig. 1. Total dissolved $\mathrm{Cu}, \mathrm{Zn}$ and $\mathrm{Cd}(\log [\mathrm{M}])$ against $\mathrm{pH}$ for all soils. Titration of soil samples with $\mathrm{HNO}_{3}$ and $\mathrm{NaOH}$. Ionic strength $(\mathrm{I})=0.02 \mathrm{M}\left(\right.$ as $\left.\mathrm{NaNO}_{3}\right)$. The observations are shown as points. The model simulations are shown as lines. The lines in left panes are predicted by DSG model, whereas the lines in right panes are predicted by DNG model. 

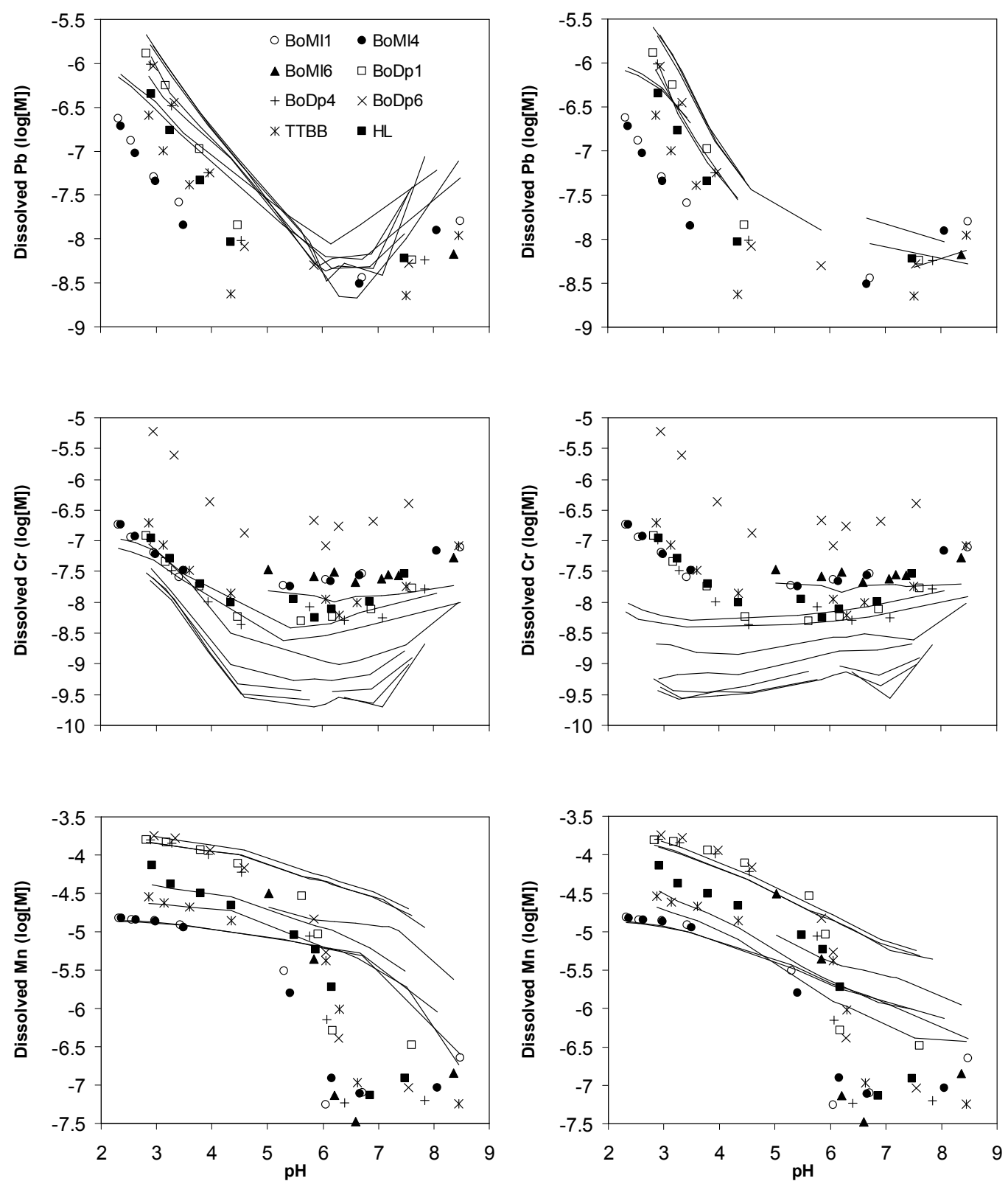

Fig. 2. Total dissolved $\mathrm{Pb}, \mathrm{Cr}(\mathrm{III})$ and $\mathrm{Mn}(\mathrm{II})(\log [\mathrm{M}])$ against $\mathrm{pH}$ for all soils. Titration of soil samples with $\mathrm{HNO}_{3}$ and $\mathrm{NaOH}$. Ionic strength (I) $=0.02 \mathrm{M}$ (as $\mathrm{NaNO}_{3}$ ). The observations are shown as points. The model simulations are shown as lines. The lines in left panes are predicted by DSG model, whereas the lines in right panes are predicted by DNG model. 

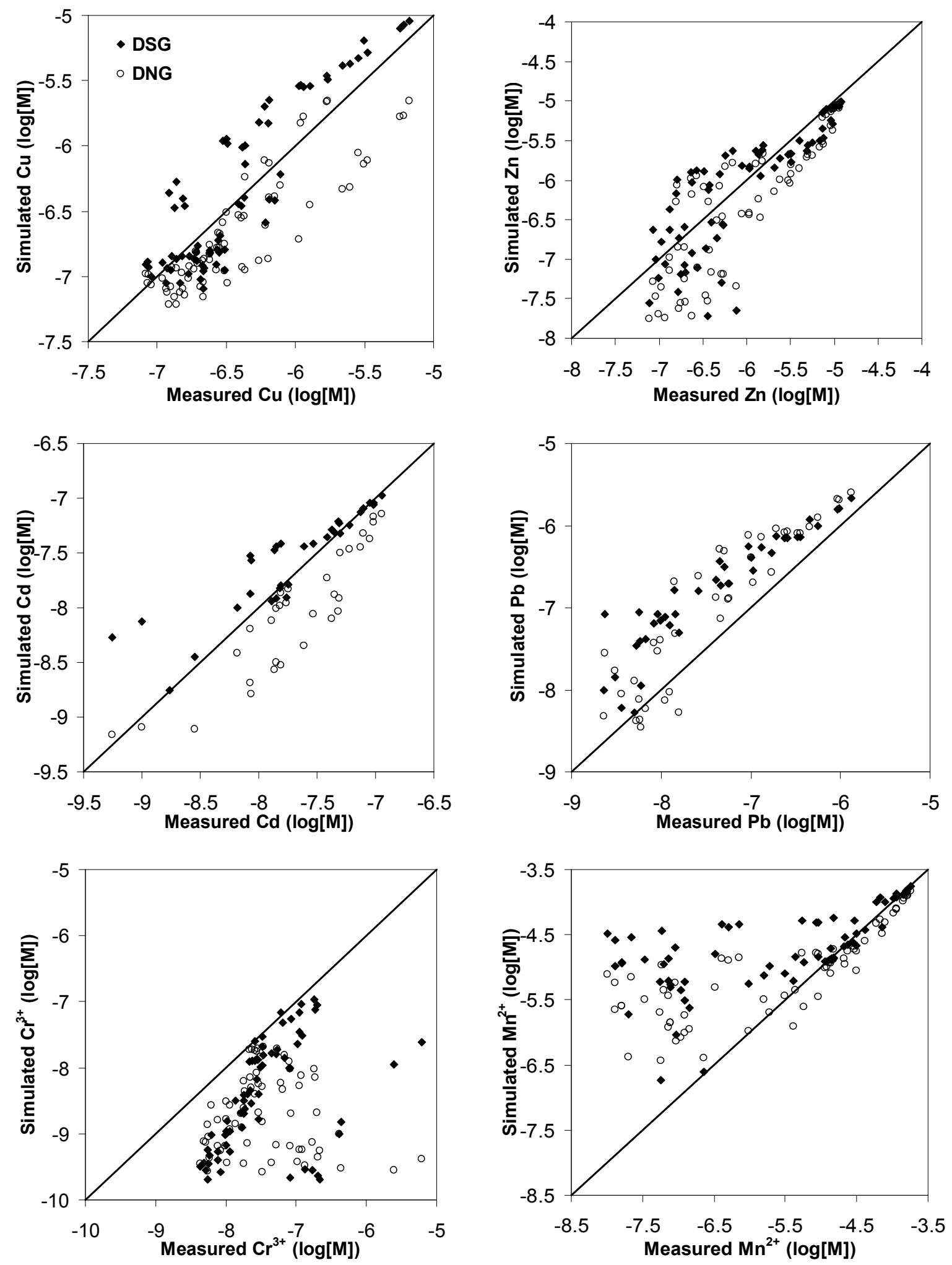

3 Fig. 3. Comparison of the simulated values of $\log [\mathrm{Cu}]_{\text {tot }}, \log [\mathrm{Zn}]_{\text {tot }}, \log [\mathrm{Cd}]_{\text {tot }}, \log [\mathrm{Pb}]_{\text {tot, }}$ $4 \log [\mathrm{Cr}]_{\text {tot }}$, and $\log [\mathrm{Mn}]_{\text {tot }}$ with measurements. The line indicates

5 the perfect 1:1 fit. 
1 Table 1. Selected properties of the investigated soil samples



$$
(\%)^{\mathrm{b}} \quad \text { Chlorite Kaolinite Illite } \text { Expandable }^{\mathrm{h}}
$$

Hanoi

$\begin{array}{lllllllllll}\text { TTBB } & \text { Wastewater } & 6.6 & 113 & 1.6 & 23 & 24 & 6 & 5 & 32 & 57\end{array}$

Nam Dinh

$\begin{array}{lllllllllll}\text { HL } & \text { Wastewater } & 6.1 & 182 & 2.7 & 45 & 46 & 6 & 7 & 40 & 47\end{array}$

Vinh Phuc Biosolid ${ }^{\mathrm{f}}$

$\begin{array}{lllllllllll}\text { BoM11 } & 0 \mathrm{t} \mathrm{ha}^{-1} & 6.1 & 43 & 0.9 & 12 & 6^{\mathrm{d}} & 5 & 11 & 11 & 73 \\ \text { BoM14 } & 30 \mathrm{tha}^{-1} & 6.2 & 35 & 1.1 & 12 & & & & \\ \text { BoM16 } & 90 \mathrm{t} \mathrm{ha}^{-1} & 7.6 & 101 & 1.3 & 13 & & & \end{array}$

Ha Tay $\quad$ Biosolid $^{\mathrm{g}}$

$\begin{array}{lllllllllll}\text { BoDp1 } & 0 \mathrm{t} \mathrm{ha}^{-1} & 6.0 & 71 & 2.2 & 35 & 36 & 5 & 9 & 30 & 56 \\ \text { BoDp4 } & 21 \mathrm{t} \mathrm{ha}^{-1} & 6.1 & 73 & 2.5 & 35 & & & & \\ \text { BoDp6 } & 63 \mathrm{t} \mathrm{ha}^{-1} & 6.1 & 80 & 2.8 & 35 & & & \end{array}$

$2 \quad{ }^{a}$ Electrical conductivity (EC) determined with 1:5 soil:deionized water ratio, $\mu \mathrm{S} \mathrm{cm}^{-1}$.

$3{ }^{\mathrm{b}}$ Total organic carbon (TOC).

$4{ }^{c_{0}} \%$ of the particle size fraction $<2 \mu \mathrm{m}$ in soil sieved through $2 \mathrm{~mm}$.

$5 \quad \mathrm{~d}_{\%}$ phyllosilicate clay minerals of the bulk soil mineralogy $(<2 \mathrm{~mm})$. In BoMl1 there was a lot

6 of quartz in the $<2 \mu \mathrm{m}$ fraction.

$7 \quad \mathrm{e}_{\%}$ of clay mineral in the $<2 \mu \mathrm{m}$ clay size fraction.

$8 \quad{ }^{\mathrm{f}}$ Chicken manure, fresh weight.

$9{ }^{\mathrm{g}}$ Muck compost - pig manure mixed with crop residues, fresh weight.

$10{ }^{\mathrm{h}}$ Expandable clay is a mixture of highly illitic mixed-layer illite-smectite/illite-vermiculite 
1 Table 2. Optimized values for model fitting parameters including $f_{\mathrm{HS}-\text { tot }}, \mathrm{FA}, \mathrm{HA}$ and $\mathrm{pH}$

\begin{tabular}{|c|c|c|c|c|c|c|c|}
\hline \multirow[t]{2}{*}{ Soil } & \multirow{2}{*}{$\begin{array}{c}\mathrm{FA}^{\mathrm{a}} \\
\left(\mathrm{g} \mathrm{kg}^{-1}\right)\end{array}$} & \multirow{2}{*}{$\begin{array}{c}\mathrm{HA}^{\mathrm{a}} \\
\left(\mathrm{g} \mathrm{kg}^{-1}\right)\end{array}$} & \multirow[t]{2}{*}{$\mathrm{pH}^{\mathrm{b}}$} & \multicolumn{2}{|c|}{ DSG } & \multicolumn{2}{|c|}{$\mathrm{DNG}$} \\
\hline & & & & $f_{\text {HS-tot }}{ }^{c}$ & Factor $^{d}$ & $f_{\text {HS-tot }}{ }^{\mathrm{c}}$ & Factor $^{d}$ \\
\hline Hanoi & & & & & & & \\
\hline ТTВB & 3.75 & 4.68 & 6.30 & 0.44 & 1.66 & 0.42 & 1.61 \\
\hline
\end{tabular}

Nam Dinh

$\begin{array}{llllllll}\text { HL } & 5.58 & 9.84 & 5.87 & 0.34 & 1.19 & 0.33 & 1.16\end{array}$

Vinh Phuc

$\begin{array}{llllllll}\text { BoM11 } & 3.57 & 2.84 & 6.05 & 0.31 & 0.88 & 0.30 & 0.85 \\ \text { BoM14 } & 3.43 & 3.13 & 6.16 & 0.28 & 0.89 & 0.27 & 0.87 \\ \text { BoM16 } & 3.66 & 3.81 & 7.19 & 0.50 & 1.74 & 0.48 & 1.67\end{array}$

Ha Tay

$\begin{array}{llllllll}\text { BoDp1 } & 5.16 & 6.98 & 5.92 & 0.39 & 1.40 & 0.39 & 1.38 \\ \text { BoDp4 } & 5.19 & 7.15 & 6.07 & 0.37 & 1.41 & 0.36 & 1.38 \\ \text { BoDp6 } & 5.18 & 7.03 & 6.06 & 0.35 & 1.51 & 0.35 & 1.50\end{array}$



$3 \quad{ }^{\mathrm{b}}$ Measured $\mathrm{pH}$ in the batch experiment for samples with no acid or alkali added.

$4{ }^{\mathrm{c}}$ The mass fraction of active humic matter (optimized value) compared to the total organic

5 matter content.

$6 \quad{ }^{\mathrm{d}}$ Ratio between the optimized value for the sum of HS and the base-extractable HS

$7 \quad(=\mathrm{HA}+\mathrm{FA})$ value. 
1 Table 3. Goodness-of-fit for the DSG and the DNG models and proportion of metal sorption

2 on different adsorbents

\begin{tabular}{|c|c|c|c|c|c|c|c|c|c|}
\hline & \multirow[t]{2}{*}{$\mathrm{n}^{\mathrm{a}}$} & \multicolumn{4}{|c|}{ DSG } & \multicolumn{4}{|c|}{$\overline{\mathrm{DNG}}$} \\
\hline & & $\mathrm{RMSE}^{\mathrm{b}}$ & $\mathrm{SOM}^{\mathrm{c}}$ & $\mathrm{HFO}^{\mathrm{c}}$ & Clay $^{\mathrm{c}}$ & $\mathrm{RMSE}^{\mathrm{b}}$ & $\mathrm{SOM}^{\mathrm{c}}$ & $\mathrm{HFO}^{\mathrm{c}}$ & Clay $^{\mathrm{c}}$ \\
\hline $\mathrm{Cu}$ & 69 & 0.36 & $86(45-99)$ & $6(0-19)$ & $8(0-55)$ & 0.29 & $98(81-100)$ & $1(0-5)$ & $1(0-19)$ \\
\hline $\mathrm{Zn}$ & 66 & 0.49 & $50(10-89)$ & $16(0-70)$ & $33(0-90)$ & 0.55 & $74(18-98)$ & $7(0-65)$ & $20(0-82)$ \\
\hline $\mathrm{Cd}$ & 31 & 0.38 & $67(15-96)$ & $7(0-43)$ & $26(0-85)$ & 0.20 & $92(54-100)$ & $<1(0-3)$ & $8(0-46)$ \\
\hline $\mathrm{Pb}$ & 40 & 0.75 & $46(5-93)$ & $51(0-95)$ & $3(0-26)$ & 0.65 & $54(5-95)$ & $42(0-95)$ & $4(0-41)$ \\
\hline $\mathrm{Mn}$ & 69 & 1.34 & $42(6-80)$ & $11(0-92)$ & $47(2-91)$ & 1.04 & $70(27-96)$ & $5(0-48)$ & $25(1-73)$ \\
\hline $\mathrm{Cr}$ & 67 & 1.28 & $49(5-99)$ & $29(0-75)$ & $22(0-95)$ & 1.56 & 100 & - & - \\
\hline
\end{tabular}

$3 \quad{ }^{\mathrm{a}}$ Number of observations above the detection limit.

$4{ }^{b}$ Root mean square error of simulated and observed logarithms of total dissolved

5 concentrations.

$6 \quad{ }^{c}$ Fractional (\%) metal adsorption on soil organic matter(SOM), iron (hydro)oxide.

7 (HFO) and clay as mean (min-max). 
2 Table S1. Parameter values for cation complexation to soil organic matter in the SHM and NICA-Donnan models

\begin{tabular}{|c|c|c|c|c|c|c|c|c|c|c|c|c|c|}
\hline Cation & \multicolumn{5}{|c|}{$\mathrm{SHM}^{\mathrm{a}}$} & \multicolumn{8}{|c|}{ NICA-Donnan $^{b}$} \\
\hline $\mathrm{Al}^{3+}$ & - & -4.0 & -9.0 & - & 1.0 & -1.05 & 0.40 & 8.89 & 0.30 & -4.11 & 0.42 & 12.16 & 0.31 \\
\hline $\mathrm{Cd}^{2+}$ & -1.6 & -9.5 & - & - & 1.3 & -0.20 & 0.73 & 0.37 & 0.54 & -0.97 & 0.68 & 0.50 & 0.50 \\
\hline $\mathrm{Cr}^{3+}$ & - & -3.75 & -7.75 & - & 1.0 & 4.3 & 0.35 & 12 & 0.27 & 2.8 & 0.35 & 20 & 0.27 \\
\hline $\mathrm{Cu}^{2+}$ & -0.55 & -6.0 & -13.6 & - & 1.4 & 2.23 & 0.56 & 6.85 & 0.34 & 0.26 & 0.53 & 8.26 & 0.36 \\
\hline $\mathrm{Pb}^{2+}$ & 0.15 & - & - & & 1.3 & 1.25 & 0.60 & 4.84 & 0.69 & -1.16 & 0.60 & 6.92 & 0.69 \\
\hline $\mathrm{Zn}^{2+}$ & -1.65 & -9.8 & - & & 1.0 & 0.11 & 0.67 & 2.39 & 0.27 & -3.84 & 0.67 & -0.73 & 0.61 \\
\hline
\end{tabular}

$3 \quad{ }^{a}$ From Gustafsson et al. (2007) and from Linde et al. (2007). ${ }^{b}$ From Milne et al. (2003). 
Table S2. Results of bulk mineralogical analysis by full-pattern fitting ( $\%$ by weight)



Eutric Fluvisol

TTBB, Ap

$\begin{array}{lllll}61.1 & 5.1 & 2.8 & 0.9 & 0.6\end{array}$

$6 \quad 0$

Eutric Fluvisol

HL, Ap

$\begin{array}{llll}32.4 & 3.5 & 2.5 & 1.4\end{array}$

$2.1 \quad 0.4$

0.9

10.7

30.4

9.4

3.1

Haplic Acrisol

$\begin{array}{lllllllllllll}\text { BoM11, Ap } & 90.9 & 0.3 & 0.8 & 0.2 & 0.2 & 0.2 & 0.0 & 1.5 & 4.8 & 0.9 & 0.2 & 0.0 \\ \text { BoM11, C } & 69.9 & 0.3 & 0.5 & 0.7 & 2.0 & 0.5 & 0.0 & 2.3 & 16.5 & 7.1 & 0.0 & 0.2\end{array}$

Cambic Fluvisol

$\begin{array}{lllllllllllll}\text { BoDp1 } & 43.6 & 4.1 & 2.4 & 1.1 & 2.3 & 0.4 & 0.4 & 9.3 & 25.9 & 5.5 & 2.3 & 2.6\end{array}$

$5 \quad{ }^{\mathrm{a} D}-2: 1$ : dioctahedral 2:1 minerals

$6 \quad{ }^{\mathrm{b}}$ Tri-2:1: trioctaedral 2:1 minerals

$7 \quad{ }^{c}$ Phyllosilicate clay minerals (in Table 1)

$8{ }^{\mathrm{d}}$ Presence of traces of gibbsite is uncertain, the main peak at $4.85 \AA \AA$ may be due to mica/vermiculite. 
9 Table S3. $\mathrm{NH}_{4} \mathrm{NO}_{3}$-extractable $\mathrm{Ca}, \mathrm{Mg}, \mathrm{Na}, \mathrm{K}$ and EDTA-extractable trace metals

$10(\mathrm{Cu}, \mathrm{Zn}, \mathrm{Mn}, \mathrm{Cd}, \mathrm{Cr}, \mathrm{Pb})$ in the studied soils (see Table 1)

11

\begin{tabular}{|c|c|c|c|c|c|c|c|c|c|c|}
\hline \multirow[t]{2}{*}{ Soil } & \multicolumn{4}{|c|}{$\mathrm{NH}_{4} \mathrm{NO}_{3}$-extractable ${ }^{\mathrm{a}}$} & \multicolumn{6}{|c|}{ EDTA-extractable $^{b}$} \\
\hline & $\mathrm{Ca}$ & $\mathrm{Mg}$ & $\mathrm{Na}$ & $\bar{K}$ & $\mathrm{Cu}$ & $\mathrm{Zn}$ & $\mathrm{Mn}$ & $\mathrm{Cd}$ & $\mathrm{Cr}$ & $\mathrm{Pb}$ \\
\hline TTBB & 0.92 & 0.23 & 0.11 & 0.17 & 9.6 & 2.7 & 22.4 & 0.10 & 0.15 & 9.2 \\
\hline HL & 1.56 & 0.21 & 0.18 & 0.10 & 13.5 & 1.7 & 42.3 & 0.13 & 0.07 & 15.2 \\
\hline BoMl1 & 0.56 & 0.04 & 0.03 & 0.02 & 3.7 & 9.2 & 12.3 & 0.03 & 0.09 & 3.3 \\
\hline BoMl4 & 0.57 & 0.06 & 0.01 & 0.01 & 4.1 & 10.5 & 12.5 & 0.02 & 0.13 & 3.8 \\
\hline BoM16 & 1.00 & 0.17 & 0.05 & 0.04 & 6.2 & 37.5 & 44.5 & 0.05 & 0.44 & 4.7 \\
\hline BoDp1 & 1.38 & 0.20 & 0.02 & 0.12 & 16.1 & 3.9 & 149.2 & 0.19 & 0.05 & 21.2 \\
\hline BoDp4 & 1.41 & 0.23 & 0.02 & 0.10 & 17.1 & 4.5 & 152.9 & 0.19 & 0.05 & 21.6 \\
\hline BoDp6 & 1.49 & 0.23 & 0.02 & 0.08 & 19.6 & 6.7 & 180.3 & 0.24 & 0.05 & 23.8 \\
\hline
\end{tabular}

12

$13{ }^{\mathrm{a}}$ Extractable with $1 \mathrm{M} \mathrm{NH}_{4} \mathrm{NO}_{3}$ (1:2.5 soil:solution ratio), $\mathrm{g} \mathrm{kg}^{-1}$.

$14{ }^{\mathrm{b}}$ Extractable with $0.025 \mathrm{M} \mathrm{Na}_{2} \mathrm{H}_{2}$ EDTA (1:10 soil:solution ratio), $\mathrm{mg} \mathrm{kg}^{-1}$. 
16 Table S4. Oxalate, dithionite and ascorbate-extractable $\mathrm{Al}$ and $\mathrm{Fe}$

17

\begin{tabular}{|c|c|c|c|c|c|}
\hline \multirow[t]{2}{*}{ Soil } & \multicolumn{2}{|c|}{$\mathrm{Al}\left(\mathrm{g} \mathrm{kg}^{-1}\right)$} & \multicolumn{3}{|c|}{$\mathrm{Fe}\left(\mathrm{g} \mathrm{kg}^{-1}\right)$} \\
\hline & Oxalate $^{a}$ & Dithionite $^{b}$ & Oxalate $^{a}$ & Dithionite $^{b}$ & Ascorbate $^{c}$ \\
\hline TTBB & 0.56 & 0.46 & 3.74 & 8.94 & 3.12 \\
\hline HL & 1.02 & 0.88 & 5.35 & 16.92 & 4.16 \\
\hline BoMl1 & 0.23 & 0.11 & 1.44 & 2.25 & 0.96 \\
\hline BoMl4 & 0.27 & 0.13 & 1.38 & 1.68 & 0.92 \\
\hline BoMl6 & 0.24 & 0.07 & 1.26 & 1.78 & 0.95 \\
\hline BoDp1 & 0.89 & 1.25 & 6.74 & 18.94 & 4.84 \\
\hline BoDp4 & 0.87 & 1.30 & 6.08 & 20.50 & 4.88 \\
\hline BoDp6 & 0.93 & 1.46 & 6.67 & 21.85 & 5.56 \\
\hline
\end{tabular}

$18{ }^{\mathrm{a}}$ Extractable with $0.2 \mathrm{M}$ ammonium oxalate (1:100 soil:solution ratio)

$19{ }^{\mathrm{b}}$ Extractable with $1.7 \%$ sodium dithionite (1:60 soil:solution ratio)

$20{ }^{\mathrm{c}}$ Extractable with $2.5 \%$ ascorbate (1:60 soil solution ratio) 

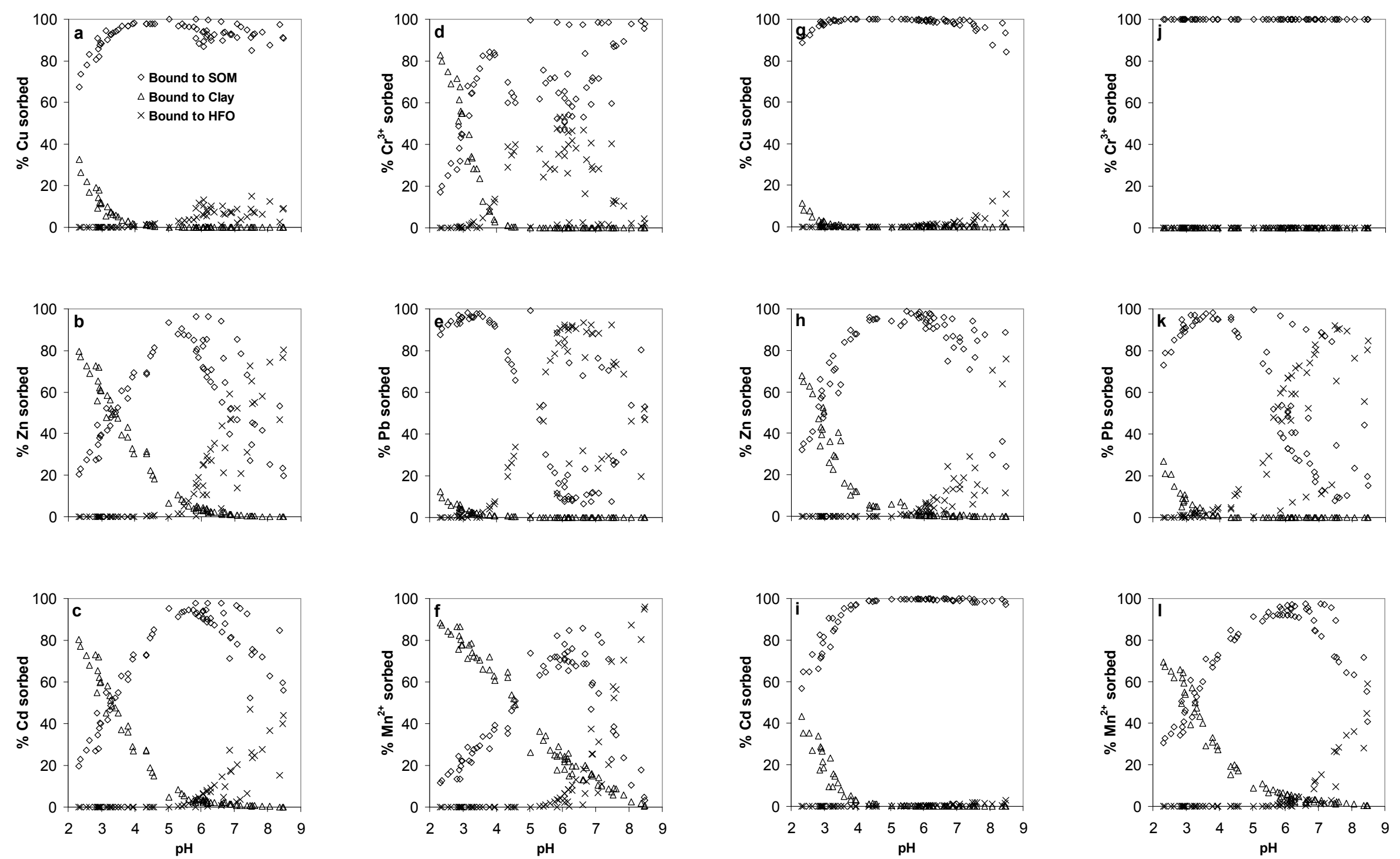

Fig. S1. Adsorption percentages (percent of total sorbed) of $\mathrm{Cu}, \mathrm{Zn}, \mathrm{Cd}, \mathrm{Cr}, \mathrm{Pb}$ and $\mathrm{Mn}$ on soil organic matter (SOM), clay and hydrous ferric oxide (HFO). Panes a-f are the predictions with the DSG model, whereas panes g-l are the predictions with the DNG model. 